\title{
Development of a Validated HPLC Method for the Simultaneous Determination of D- and L-Thyroxine in Human Plasma
}

\author{
Jing Yu Jin, Chae-Sun Baek, and Wonjae Lee*

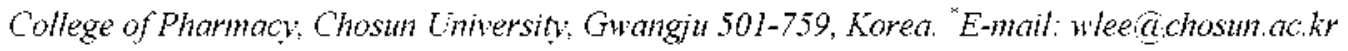 \\ Recened April 4, 2007
}

Key Words : Thỵroxine. Enantiomer separation. Chiral stationary phase

L-Thyroxine (L-T4). the naturally occurring thyroid hormone has been used for the treatment of thyroid dysfunctions. while D-T4 is not active in the thyroid and is used for the treatment of hyperlipidenia. ${ }^{1.2}$ Therefore. a convenient and reliable enantiomer separation method has been of great interest in the biological and pharmacological research field. Several groups reported the chromatographic resolution of thyroxine enantiomers by chiral ligand exchange method using cupper solution on achiral column. ${ }^{3-s}$ However, only a few of results for direct enantiomer separation on chiral stationary phases (CSPs) have been reported $^{2,0-8}$ Among these reports. the separation of thyroxime enantioners has been performed on a proline derived CSP ( $\alpha=1.90)$. a protein ovonucoid derived CSP ( $\alpha=$ 1.16-1.32) under aqueous buffer solutions and on a CSP derived from $(+)-(18-c r o w n-6)-2,3.11 .12$-tetracarboxylic acid (18-C-6-TA) $(\alpha=2.08-3.11)$, depending upon the used mobile phases ${ }^{2,6-8}$ For resolution of thyroxine enantioners, the crown ether derived CSP showed better enantioseparation than the proline or ovomucoid derived CSP. However. the validated direct determination of thyroxine enantioners in plasma on a CSP derived from 18-C-6-TA (CSP 1) has not been performed. In this study, a liquid chromatographic method for the sinultaneous determination of D- and Lthyroxine in human plasma using the chiral crovnl ether derived CSP 1 is developed and validated. To our hiowledge. the validated direct simultaneous determination of thyroxine enantiomers in plasma samples using the chiral HPLC colunin is the first report.

For the optimum clromatographic results of specificity experiment of D- and L-Tt in plasna samples. several mobile phase conditions were used. As shown in Table 1 , chromatographic parameters such as separation factors. retention times and resolution factors on CSP 1 are considerably influenced by the nature of mobile phases. ${ }^{7.5}$ Although Aboul-Enein and his co-works have shown the chromatographic results using the mobile phases of methanol $/ \mathrm{H}_{2} \mathrm{O}$ containing $\mathrm{H}_{2} \mathrm{SO}_{4}$ as an additive. ${ }^{7}$ these chromatographic conditions were not effective for the specificity results of $\mathrm{D}$ - and $\mathrm{L}-\mathrm{T} 4$ present in plasma samples. Therefore, the several mobile phases of ethanol $/ \mathrm{H}_{2} \mathrm{O}$ containing $\mathrm{H}_{2} \mathrm{SO}_{4}$ as an additive were used and optimized in this study. When the mobile phase of $90 \%$ ethanol $/ \mathrm{H}_{2} \mathrm{O}(\mathrm{V} / \mathrm{V})$ containing 10 $\mathrm{mM} \mathrm{H} \mathrm{SO}_{4}$ was used for the validation study of $\mathrm{D}$ - and $\mathrm{L}-\mathrm{T} 4$ in plasma samples, no matrix peaks interfered with internal standard (IS) of L-phenylglycine, L-T4 and D-T4 at their retention times. Figure 1 shows representative cluromato-

Table 1. Effect of mobile phase for the separation of the enantiomers of thy roxine on CSP1

\begin{tabular}{|c|c|c|c|c|c|}
\hline Alcohol/Hz & Acid Additive & $B_{1}^{\prime \prime}$ & $k_{2}^{\prime}$ & $\alpha^{h}$ & $\mathrm{Rs}^{\prime}$ \\
\hline $75 \%$ Ethanol/ $\mathrm{H}_{2} \mathrm{O}$ & $10 \mathrm{mM} \mathrm{H}_{2} \mathrm{SO}_{4}$ & 1.48 & 2.69 & 1.82 & 3.12 \\
\hline $80 \%$ Ethanol/ $\mathrm{H}_{2} \mathrm{O}$ & $10 \mathrm{mM} \mathrm{H}_{2} \mathrm{SO}_{4}$ & 1.69 & 3.12 & 1.85 & 3.43 \\
\hline $85 \%$ Ethanol $/ \mathrm{H}_{2} \mathrm{O}$ & $10 \mathrm{mM} \mathrm{H}_{2} \mathrm{SO}_{4}$ & 2.47 & 4.57 & 1.85 & 3.68 \\
\hline $90 \%$ Ethanol/ $/ \mathrm{H}_{2} \mathrm{O}$ & $10 \mathrm{mM} \mathrm{H}_{2} \mathrm{SO}_{4}$ & 6.23 & 12.00 & 1.92 & 4.31 \\
\hline $80 \%$ Methanol/ $\mathrm{H}_{2} \mathrm{O}$ & $10 \mathrm{mM} \mathrm{H}_{2} \mathrm{SO}_{4}$ & 1.00 & 1.91 & 1.92 & 2.67 \\
\hline $80 \%$ Ethanol/H2 & $5 \mathrm{mM} \mathrm{H}_{2} \mathrm{SO}_{4}$ & 1.34 & 2.64 & 1.96 & 2.89 \\
\hline $100 \%$ Methanol & $10 \mathrm{mM} \mathrm{H}_{2} \mathrm{SO}_{4}$ & 2.05 & 4.35 & 2.12 & 305 \\
\hline
\end{tabular}

Mobile phase: Alcohol $\mathrm{H}_{2} \mathrm{O}(\mathrm{V} / \mathrm{V})$ containing acid additive: Flow rate $=$ $1 \mathrm{~mL}$ min: $U V=210 \mathrm{~nm}$. "Capacity factor for the first eluted enantiomer. "Separation factor. 'Resolution factor.
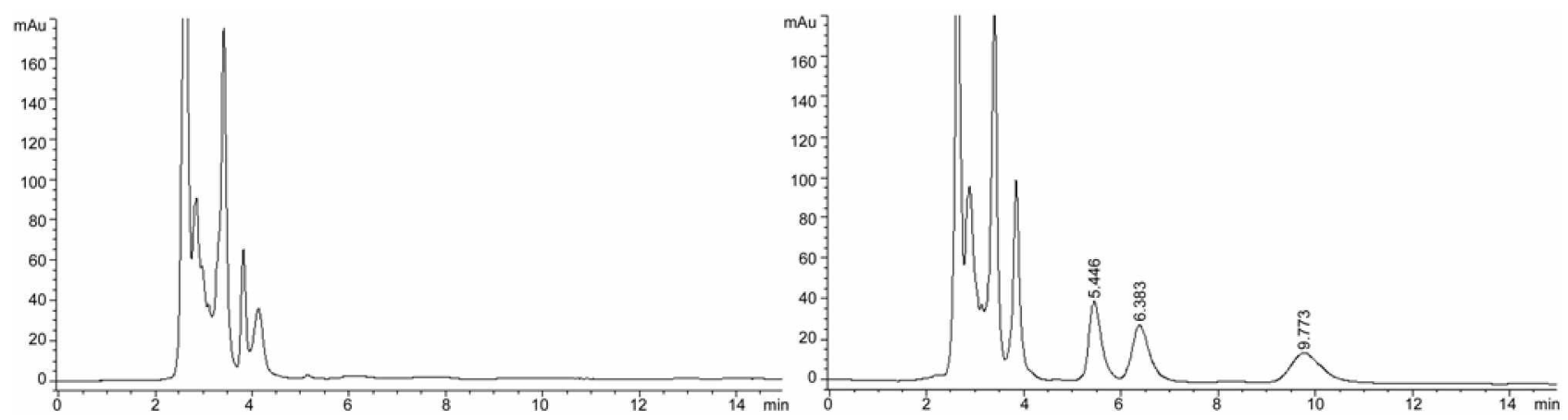

Figure 1. Chromatograms of a blank human plasma sample (the left) and a typical plasma sample spiked with IS (50/tg/mL, $5.446 \mathrm{~min})$, L$\mathrm{T} 4(20 / \mathrm{gg} / \mathrm{mL}, 6.383 \mathrm{~min})$ and $\mathrm{D}-\mathrm{T} 4(20 / \mathrm{g} / \mathrm{mL}, 9.773 \mathrm{~min})$ (the right $)$ See experimental for chromatographic conditions. 

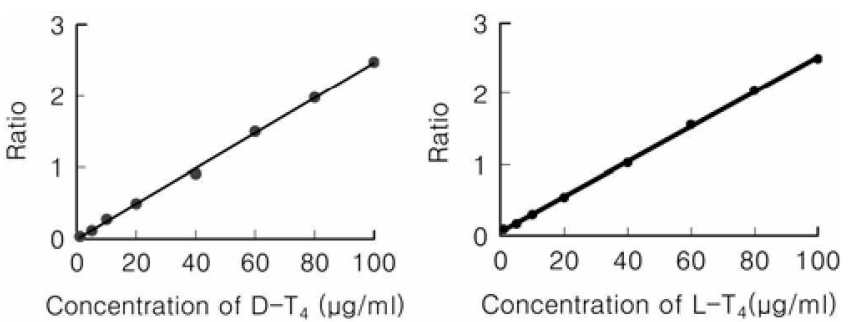

Figure 2. Calibration curve of D-T4 (the left) and L-T4 (the right) spiked to blank plasma. The coefficients of correlation ( $\mathrm{r}$ ) were 0.9987 and 0.9996 for D-T4 and L-T4, respectively

grams of a blank human plasma sample and a typical plasma sample spiked with IS, L-T4 and D-T4 after pretreatment of samples. The calibration curves were constructed for demonstrated the linear relationship between the relative peak area and the concentration of D- and L-T4 standard serum solutions. Each eight standard solution (1. 5, 10. 20 . 40. $60.80,100 \mu \mathrm{g} / \mathrm{mL}$ ) of D- and L-T4 was rul for the calibration curve, respectively. As shown in Figure 2. the coefficients of correlation (r) were 0.9987 and 0.9996 for D$\mathrm{T} 4$ and $\mathrm{L}-\mathrm{T} 4$ over the concentration ranges of $1-100 \mu \mathrm{g} / \mathrm{mL}$. respectively. The equations were $\mathrm{Y}_{\mathrm{D}-\mathrm{T} 4}=0.0247 \mathrm{X}_{\mathrm{D}-\mathrm{T} 4}-$ 0.0067 and $\mathrm{Y}_{\mathrm{L}-\mathrm{I}^{-}+}=0.0246 \mathrm{X}_{\mathrm{L}-14}+0.054$ [Y for peak area ratio to IS and $\mathrm{X}$ for concentration $(\mu \mathrm{g} / \mathrm{mL})$ ]. These results are better than those by the other group of the analytical method using a chiral mobile phase additive on a silica column. ${ }^{*}$

Tables 2 and 3 show a sumumary of intraday and interday precision and accuracy of measurement of D-T4 and L-T4 in plasmia. respectively. The intraday accuracy was determined to be $97.6-103.4 \%$ (D-T4) and $97.1-102.0 \%$ (L-T4) by performing five replicate analyses at each concentration level $(10.20 .40 .100 \mu \mathrm{g} / \mathrm{mL})$, respectively. The intraday precision expressed in \% RSD was deternined to be 1.68 $8.27 \%(\mathrm{D}-\mathrm{T} 4)$ and $1.96-6.54 \%(\mathrm{~L}-\mathrm{T} 4)$ at the same four concentration levels. respectively. Similarly the interday accuracy was determined to be $97.8-108.4 \%$ (D-T4) and 98.9-100.2\% (L-T4) by performing five replicate analyses at

Table 2. Intraday precision and accuracy of D- and L-T4 in standard plasma samples

\begin{tabular}{cccc}
\hline Added & \multicolumn{3}{c}{ Intra-day $(\mathrm{n}=5)$} \\
\cline { 2 - 4 } $\begin{array}{c}\text { Concentration } \\
(\mu \mathrm{g} / \mathrm{mL})\end{array}$ & Mean $(\mu \mathrm{g} / \mathrm{mL})$ & Accuracy $(\%)$ & Precision $(\%)$ \\
\hline D-T4 & & & \\
10 & 10.34 & 103.4 & 6.67 \\
20 & 19.53 & 97.7 & 8.27 \\
40 & 39.02 & 97.6 & 1.68 \\
100 & 99.63 & 99.6 & 5.67 \\
& & & \\
L-T4 & & & 6.54 \\
10 & 10.20 & 102.0 & 4.63 \\
20 & 19.41 & 97.1 & 1.96 \\
40 & 39.77 & 99.4 & 6.41 \\
100 & 98.10 & 98.1 &
\end{tabular}

Table 3. Interday precision and accuracy of D- and L- T4 in standard plasma samples

\begin{tabular}{cccc}
\hline Added & \multicolumn{3}{c}{ Inter-day $(\mathbf{n}-5)$} \\
\cline { 2 - 4 } $\begin{array}{c}\text { Concentration } \\
(\mu \mathrm{g} / \mathrm{mL})\end{array}$ & Mean $(\mu \mathrm{g} / \mathrm{mL})$ & Accuracy $(\%)$ & Precision $(\%)$ \\
\hline D-T4 & & & \\
10 & 10.84 & 108.4 & 7.07 \\
20 & 20.63 & 103.2 & 4.42 \\
40 & 39.13 & 97.8 & 1.52 \\
100 & 101.87 & 101.9 & 3.35 \\
& & & \\
L-T4 & & & \\
10 & 9.96 & 99.6 & 7.99 \\
20 & 20.04 & 100.2 & 8.32 \\
40 & 39.54 & 98.9 & 6.49 \\
100 & 99.93 & 99.9 & 8.25 \\
\hline
\end{tabular}

each concentration level (10. 20. $40,100 \mu \mathrm{g} / \mathrm{mL}$ ), respectively. The interday precision expressed in \% RSD was determined to be $1.52-7.07 \%$ (D-T4) and $6.49-8.32 \%$ (L-T4) at the same four concentration levels. respectively. The limit of detection was defined as the peak signal of D-T4 and LT4 equal to three times the average noise level. The limit of detection for both D- and L-T4 in plasma sample were 1.8 $\mathrm{ng}$ and $3.2 \mathrm{ng}$ per injected sample, respectively.

In summary. we demonstrated the simultaneous determination of D-T4 and L-T4 on a chiral crown ether derived CSP 1 in human serum with base-line separation. This new analytical method for the determination of D-T4 and L-T4 using internal standard has been developed and validated. Validation experiments have shown that this method has good precision and accuracy as well as high linearity of 0.9987 and 0.9996 for D-T4 and L-T4 over the concentration ranges of $1.100 \mu \mathrm{g} / \mathrm{mL}$. respectively. This new analytical results using the chiral HPLC column may be used to investigate not only the simultaneous determination of D-T4 and L-T4 for biological samples but also the degree of conversion of each $\mathrm{T} 4$ enantiomer in vivo.

\section{Experimental Section}

Reagents and Apparatus. L-Thyroxine and L-phenylglycine were purchased from Aldrich (WI. USA) and DLthyrroxine was purchased from TCI (Japan). Human plasma was obtained from Red Cross Blood Center (Gwangju. Korea). HPLC-grade alcohols and acetonitrile were purchased from J. T. Baker (PA. USA). All clromatographic measurements were performed using an Agilent 1100 series combinatorial LC instrument equipped with isocratic pump. auto-sampler and diode array detector from Agilent Technologies (Wilmington. DE, USA). Water was purified using a milli-Q water purification system (Bedford. MA. USA). CSP 1 derived from $(+)-18-C-6-T A(250 \mathrm{~mm} \mathrm{~L} \times 4.6 \mathrm{~mm}$ I.D.) was obtained from RS Technologies (Daejon. Korea). Chromatographic conditions are as follows: flow rate $=1$ $\mathrm{mL} / \mathrm{min}$ : detection UV $210 \mathrm{~nm}$ : Temperature ambient (about 
$\left.25^{\circ} \mathrm{C}\right) ; 20 \mu \mathrm{L}$ injection volume. The mobile phase used for validation data is $90 \%$ ethanol/ $\mathrm{H}_{2} \mathrm{O}(\mathrm{V} / \mathrm{V})$ containing 10 $\mathrm{mM} \mathrm{H}_{2} \mathrm{SO}_{4}$.

Sample Preparation. A stock solution of DL-thyroxine $(2.4 \mathrm{mg} / \mathrm{mL}$ ) and L-phenylglycine (internal standard. 0.6 $\mathrm{mg} / \mathrm{mL}$ ) dissolved with the mobile phase were prepared. From the stock solution. DL-thyroxine working standard solutions of $0.024,0.12,0.24,0.48,0.96,1.44 .1 .92,2.40$ $\mathrm{mg} / \mathrm{mL}$ were prepared by dilution with the mobile phase. Plasma samples $(0.2 \mathrm{~mL})$ were pipetted into glass tubes and spiked with $20 \mu \mathrm{L}$ of each thyroxine working standard solution and intenal standard (IS) solution, respectively. Then standards in plasma at eight different concentration levels $(1,5,10,20,40.60 .80,100 \mu \mathrm{g} / \mathrm{mL})$ of D- and Lthyroxine were prepared for calibration curves, respectively. After adding $0.5 \mathrm{~mL}$ of acetonitrile to glass tube, the plasma samples were shaken for $1 \mathrm{~min}$. After $10 \mathrm{~min}$ of centrifugation at $3000 \mathrm{~g}$. the supernatant $(0.5 \mathrm{~mL})$ was transferred into another glass tube and completely evaporated under a stream of nitrogen. The dry residue was reconstituted with $400 \mu \mathrm{L}$ mobile phase and centrifuged for $2 \mathrm{~min}$ at $15000 \mathrm{~g}$. And the upper layer $(20 \mu \mathrm{L})$ wad injected directly onto the HPLC system. Five replicate analyses were performed on plasma standards at four different concentration levels ( 10 .
$20,40.100 \mu \mathrm{g} / \mathrm{mL}$ ) of D-and L-thyroxine, respectively. to assess both interday and intraday precision and accuracy of the method.

Acknowledgment. This study was supported by research funds from Chosun University. 2006.

\section{References}

1. Gika. H.: Lämmerhofer. M.: Papadoyantiss. I.: Lindner. W. J. Chromatogr: B 2004. 800.193.

2. Abou-Basha, L. I.: Aboul-Enein, H. Y. Pham. Acta Helv 1995. 70.237.

3. Oelrich. E.: Preusch. H.: Wilhelm. E. J. High Resol. Chrontato. 1980. 3. 269.

4. Hay. I. D.: Atnesley. T. M.: Jiang. N. S.: Gorman. C. A. J. Chromatogr: B: Bioned. $1981,226,383$.

5. Wang, R.; Jia, Z.-P.; Hu, X.-L.: Xul. L.-T; Li, Y.-M:; Chen. L.-R. J. Chromatogr: $B$ 2003. 785,353 .

6. Ekborg-Ott. K. H.: Kullman. J. P.: Wang. X.: Gahm. K.: He. L.: Armstrong. D. W. Chirality 1998. 10.627.

7. Aboul-Enein. H. Y.: Ali. I.: Hyun. M. H.: Cho. Y. J.: Jit1. J. S. J. Biochem. Bioph. Hethods $\mathbf{2 0 0 2}, 54.407$.

8. Jin. J. Y.; Lee. W.: Hyun. M. H. J. Liq. Chrom \& Rel. Tech 2006. 29. 841

9. Hyun. M. H. Bull. Korean Chem. Soc. 2005. 26, 1153. 